\title{
Three Distributive Problems of the Twenty Fist Century: Inequality, Social Scarcity, and Environmental Decay
}

\author{
Author: Justin P. Holt
}

The final version of this article was published in Critique in 2016.

\begin{abstract}
This paper will examine the three distributive problems of inequality, social scarcity, and environmental decay. All three of these problems are the result of economic growth that is not properly structured by institutions. It will be argued that each one of these distributive problems exacerbates the other two. Any solution to one of these problems must address the other two as well. This paper will show that these three distributive problems can be minimized through a combination of tax measures, institutional changes, public employment creation, public service provision, and the nationalization of certain industries.
\end{abstract}

Keywords: Fred Hirsch; Inequality; Social Scarcity; Environmental Decay; Job Guarantee; Public Provision

\section{Introduction}

Fred Hirsch in his landmark work Social Limits to Growth argued that distributive problems are not simply related to material inequality or to the exhaustion of natural resources. Rather, Hirsch found that the growth of income brings about a particular kind of distributive conflict arising from social congestion; this results in the social scarcity for certain goods such as land and positions. Hirsch described the problem as such: 
Congestion is most apparent in its physical manifestation, in traffic jams. But traffic congestion can be seen as only a special case of the wider phenomenon of social congestion, which in turn is a major facet of social scarcity. Social scarcity is a central concept in this analysis. It expresses the idea that the good things of life are restricted not only by physical limitation of producing more of them but also by the absorptive limits on their use. Where the social environment has a restricted capacity for extending use without quality deterioration, it imposes social limits to consumption. More specifically, the limits are imposed on satisfactions that depend not on the product or facility in isolation but on the surrounding conditions of use. ${ }^{1}$

Key examples of the problem of social scarcity are the crowding of suburban areas and public parks, and the screening of leadership positions. Suburban housing areas are characterized by their spacious living conditions without the absence of services indicative of rural areas. If a suburban area becomes too densely populated, it loses its suburban characteristics, and its desired features are lost. The overuse of a suburban area destroys the consumable goods which define it. Other cases of such crowding include the use of urban parks. The desired consumable goods of an urban park are the enjoyment of rustic landscapes, a modicum of solitude, and the space available for picnics and athletic activities. However, if a park becomes too crowded the landscapes can become destroyed, the solitude is drowned out by radios and chatter, picnicking families are squeezed in next to one another, and there is no room for athletic pursuits. As Hirsch notes above, the traffic jam demonstrates social congestion. As more autos enter into service the consumable good of personal motorized transport declines. Instead of travel being accomplished in a fast, comfortable, and individualized manner, travel becomes slow,

1 Fred Hirsch, Social Limits to Growth, A Twentieth Century Fund Study (Cambridge, Massachusetts: Harvard University Press, 1976), p. 3. 
uncomfortable, subject to the travel choices of others, and the capacity for the state and private entities to provided sufficient roadways and parking.

Another example indicative of the topic of this paper is the screening of leadership and other elite posts to preserve the nature of these posts. Leadership positions are defined by a particular monopoly of authority. If more people perform these functions the authority becomes dissipated. If these leadership positions must be unique in their concentration of authority then the dissipation of this authority degrades the usefulness and quality of its activity. If there are many claimants to a leadership post and the duties of the post cannot be usefully distributed then a selection mechanism is required. Potential claimants can be sorted and screened according to their credentials. If these positions are desired by many, there will be a heightened attempt to gain the currently required credentials. This will result in an oversupply of candidates. An increase in the required credentials to qualify in turn brings about more accumulation of credentials. Hirsch finds such credential races to be a waste of real resources and a social waste manifesting as the disappointment in unachieved expectations. ${ }^{2}$

The problem of social congestion is a distributive dilemma, which economic growth is not a solution for. As the above examples show economic growth can exacerbate the problems of social scarcity. Increasing the density of suburbs destroys their consumable goods. Whereas building new rings of suburbs makes their amenities less desirable due to the increased commuting time. One spends more time in autos, buses, and trains and less time in their yards and suburban forest preserves. In a related sense, as society develops and more people accumulate education credentials, more social congestion occurs at the screening point to top positions. According to Hirsch's theory, economic growth produces a mass of underutilized educated individuals who have used real resources to obtain their unusable degrees due to the impossibility of reproducing positional goods.

This paper will argue that the distributive problem of social scarcity is exacerbated by, and itself

$2 \quad$ Ibid., p. 51. 
also drives, the distributive problems of economic inequality and environmental decay. Hirsch himself notes this in regard to inequality in the final pages of his book. ${ }^{3}$ Social scarcity for positions, land, and resources causes people to increase their credentials and to seek more economic growth to keep up with the competition. Real resources - in human capital, human made capital, and natural capital - are used to compete for socially scarce goods. Inequality makes scarce positions more valuable, and this further drives competition for positions and credentials. In addition, inequality can drive greater throughput of natural resources in pursuit of greater economic security and attempts to maintain habitual and social validated levels of consumption. Ecological decay from a loss of natural resources causes increased competition for resources, land, employment, income, and wealth. This also drives the pursuit of credentials to gain coveted positions or to qualify as employable.

The first section of the paper will present how the distributive problems of social scarcity, inequality, and ecological decay form a feedback effect that exacerbates these problems. The second part, will address an additional theme considered by Hirsch, the under provision of public services and their cumulative replacement by private services. The third part will be an overview of Hirsch's recommendations for the alleviation of social congestion. In the fourth section, additional possible solutions to the distributive conflicts associated with social congestion, environmental decay, and inequality will be considered with an overview of the policy of a job guarantee to maintain full employment. The paper will conclude with some final comments.

\section{1: The Problem}

This section of the paper will present how the distributive problems of social scarcity, inequality, and ecological decay from a feedback loop which exacerbate these problems. As total income grows and as industry becomes more productive, there is a tendency for inequality, natural resource throughput, and

$3 \quad$ Ibid., p. 181. 
social congestion to increase. It is important to note that there is a tendency for the above to occur if there are no counteracting institutional mechanisms to employ those rendered redundant by productive growth, to influence the rate of natural resource use, and to minimize the effect of positional competition, such as pay limits. ${ }^{4}$ Income growth is not the only cause of these distributive problems, as each of the three intensify they also exacerbated the others, but it can be understood as an ultimate and not proximate cause. The remainder of this section will describe these feedback effects as well as the underlying market failure which lies at the root of them.

Social congestion results because the positional goods which are competed for, land and elite posts, are by their nature limited, according to Hirsch. ${ }^{5}$ As societies become wealthier, in the sense of producing more materially reproducible consumer items, the demand for these material goods tends to decline and the demand for positional goods increases. The income consumption curves of material reproducible goods - food, autos, mechanical-electrical conveniences, etc - are logarithmic in shape, that is their consumption increases at a decreasing rate. This logarithmic shape demonstrates that as people's incomes increase, their consumption of materially reproducible goods as a component of total consumption decreases. The reasoning behind this conjecture is clear, there is a limit to the amount of basic foodstuffs a person can consume. The same applies to the useful consumption of autos, stereos, refrigerators, washing machines, and similar items.

Positional goods, those goods which are limited by their nature and the consumption of which can produce social congestion, are consumed in increasing proportion as income increases. This relationship could be exemplified by the curve of a power function greater than one. Consumption of positional goods increases at an increasing rate as income increases. As people's income increases the marginal change in their consumption of materially reproducible goods decreases, while the marginal

4 Ibid., p. 183.

5 Hirsch argues that all positional goods, land and elite posts, can't be produced like material goods: cars, refrigerators, televisions, and so forth. 
change in their consumption of positional goods increases. Since positional goods are limited by nature, the competition for elite posts and land intensifies and cannot be alleviated by increased production.

The result of this increased competition for socially scarce goods is to use real goods to facilitate the consumption of these positional items. One must have more and increasing income to obtain and keep positional goods. Whereas materially reproducible items become, on average, cheaper as national income grows. This search for increasing amounts of income reinforces social congestion, but it also has two residual effects: the exacerbation of inequality and environmental decay.

Economic inequality becomes more pressing as elite positions become filled with more highly credentialed individuals, that seek high incomes to consume positional goods. This is the result because the positions below the elite post become filled, in turn, with the highly credentialed individuals which were not selected. This pushes the less credentialed individuals who used to occupy these secondary positions into ones where they themselves are now overqualified. If these new lower posts do not have the level of remuneration of the former higher posts, the real and felt inequality becomes exacerbated as the less qualified increasing occupy lower pay and lower prestige positions and the ranks of the chronically unemployed. Social congestion of elite position increases the pool of underutilized talent.

Inequality itself is driven by structural changes which slow the process of net employment creation. ${ }^{6}$ This results in an increase in social scarcity for posts as more people attempt to accumulate credentials to compete in the new employment constrained environment. There are two casual processes that exacerbate social scarcity and inequality. First, economic growth increases the supply of credentialed candidates which cannot all be employed in positions that fully utilize their level of

6 There are many reasons that mature capitalist economies are chronically demand constrained. There can be simultaneously structural unemployment as well as demand cyclical unemployment. Both causes of unemployment are the result of policy failures. Maintaining full employment through the use of a job guarantee will be considered in the fourth section of this paper. On demand constraint see William Mitchell William and Joan Muysken, Full Employment Abandoned: Shifting Sands and Policy Failures (Cheltenham, UK and Northampton, MA, USA: Edward Elgar, 2008). 
training. This process increasingly crowds the less elite positions and puts downward pressure on wages and increases the social waste of unattained expectations. ${ }^{7}$ Second, productivity increases result in a slowing of the net creation of new employment. ${ }^{8}$ As competition for employment increases people respond by increasing their credentials. This in turn, exacerbates the social congestion of elite posts and crowds out people with lesser credentials in lower posts. The net effect is the creation of involuntary unemployment and the underemployment of individuals overqualified for their current positions. As with the first cause, economic inequality has been exacerbated and felt loss has increased through social waste.

The search for higher incomes will increase environmental decay indirectly and directly. As individuals seek higher incomes to consume positional goods, this income will cause increased throughput of natural resources, since growth is currently linked to the use of natural resources. Even if one attempts to make all of one's money income in a sustainable fashion it is inevitable that the money that one spends will be spent by others on goods and services that are the result of increased throughput of natural resources. Income growth is concurrent with the growth of throughput. Additionally, environmental decay becomes exacerbated by the social scarcities of land crowding and credential screening. As land becomes more crowded, resource use increases as fuel is wasted in traffic jams or in longer commuting times. As crowding intensifies, more land becomes occupied as people are pushed out of inner ring settlements. Increased competition for select positions drives the pursuit of credentials which are obtained through real resources in their production and financing. As more people pursue limited elite positions they must finance their competition for credentials through greater real assets,

7 Hirsch, Social Limits to Growth, op. cit., pp. 6-7, pp. 49-50, and p. 170.

8 Michael Murray, 'Effective Demand, Technological Change, and the Job Guarantee Program,' in Michael J. Murray and

Mathew Forstater, editors, The Job Guarantee: Toward True Full Employment (New York: Palgrave Macmillan, 2013), pp. 95-124. Santosh Mehrotra and Enrique Delamonica, Eliminating Human Poverty: Macroeconomic and Social Policies for Equitable Growth (London and New York: Zed Books and International Studies in Poverty Research, 2007). 
directly or indirectly.

For example, a parent who seeks to increase the chances of their child's admission into a prestigious university can do so by purchasing pre-college credentials: selective prep schools, tutoring, and social activities. These preparations can include the cost of living in the correct neighborhood (close to the private school or in the right public school district). To afford such a competitive posture, parents need growing incomes. These growing incomes require economic growth, which results in the throughput of natural resources. Thus, to compete for social position is commensurate with ecological decay given our current economic-technological apparatus.

It is important to point out that even if social scarcity is not considered, inequality itself drives environmental decay. The loss of natural resources can heighten people's attempts to alleviate inequality through increasing natural resources throughput. A feedback loop of exacerbating inequality and ecological decay can obtain even without the pressures of social congestion.

Hirsch was interested in considering why people people choose these consumption patterns which result in aggregate real and felt losses. The decision to increase one's credentials or one's income, as others do the same, results in a situation where, at best, people are relatively in the same position as before, or at worst, these decisions have resulted in a loss of real resources and social waste. The competitive pursue of socially scarce goods is compositional problem which Hirsch called piecemeal choice:

The core of the problem is that the market provides a full range of choice between alternative piecemeal, discrete, marginal adjustments, but no facility for selection between alternative states. Since the piecemeal choices between the opportunities that are available through market transactions at any given time involve unintended and at times undesired repercussions, choice in the small does not provide choice in the large. For 
example, as public transportation deteriorates, we are given an extra incentive to use our own private mode of transport which in turn results in further deterioration and a worsened position of public vis-à-vis private transportation. The choice is posed at each stage in a dynamic process; there is no chance of selection between the states at either end of that process. By contrast, the political mechanism, through which preferences between alternative states could in principle be posed, has not yet developed a satisfactory system for such decision. ${ }^{9}$

The compositional problem of piecemeal choices arises when an individual chooses a unit of consumption that would provide satisfaction in isolation, but when numerous people make the same choice their consumption renders less satisfaction than it would in isolation. Traffic jams exemplify the problem. In isolation a beautiful weekend is a perfect time to drive your car to the beach, since it is only an hour away. However, if many people make the same choice, based on the same considerations, then the one hour trip turns into a two or three hour one.

The result of a traffic jam is commonly anticipated by beachgoers, but the results of other aggregated choices can be difficult to anticipate particularly when the result is an alternative state. Hirsch's example of a decaying public transport system can exemplify how the results of certain piecemeal choices may be anticipated, but not the changed state, which is the cumulative result of piecemeal choices. The anticipated results of choosing not to ride public transportation are the time and costs of using one's own auto given the current road usage rates. However, the changed state that would result as the cumulative result of the piecemeal choices of less and less people not using public transport and its eventual decommissioning is not only increased driving time and costs for all car drivers. It is also difficult to anticipate or unanticipated results: the new near impossibility of finding 
parking or the loss of certain members of the workforce who were unable to afford the transition to personal transport.

Such anticipated changes of states due to aggregated piecemeal choices in the context of social scarcity are not only that increased credentialing results in the same relative position, ${ }^{10}$ but also that people don't become relatively wealthier with a more educated workforce. They become relatively poorer, if there are no institutions in place to minimize the effects. Society does not address its ecological problems in a more reasonable manner with its better educated workforce, rather, the process of creating this workforce results in increased demands on natural resources. If this workforce maintains its pursuit of elite positions and other positional goods they have no choice but to intensify their use of nature to finance their consumption. Thus, people have a piecemeal choice of how many credentials they can pursue or how much natural resources they can throughput, but they do not have the choice of secure incomes without participating in a credential race, and they do not have the choice of an industrial process which would use less throughput overall.

As Hirsch noted at the end of the above quoted passage, he found that there is no known suitable political mechanism to implement a decision from one state purposefully into another desirable state. Humanity will transition from one technological apparatus to another, but will the new state of affairs be desirable? Or, will the technological apparatus be the result of piecemeal choices due to positional competition facilitated by increasing natural resource throughput with ecological degradation and widening inequality as the byproducts? Seemingly, the latter appears to be our apparent course.

\section{2: Public and Private Services}

10 That is exemplified by Hirsch's commonly used example that if everyone stands on their tip toes to get a better look the previous view is relatively maintained. 
Hirsch found that one of the key problems associated with social congestion and piecemeal choices is a tendency towards commercialization. Hirsch notes that positional

... competition not only draws resources away form the output of final consumption goods and services in the commercial sector; it also draws resources away form the noncommercial sector, from activities that remain partly or wholly outside the market and the cash nexus. These activities include subsistence production (production for one's own use rather than for sale), formal or informal grants in goods or kind, and leisure. $^{11}$

The intensification of commercialization results in privatization of public services, promotion of self interest, and the erosion of social feeling and friendship. The increase in positional consumption of the above tendencies is due to its personal nature. If one opens one's country estate to the public, if entry into one's profession become less restricted, or if an elite post no longer coincides with a high salary these goods' positional qualities decline. To retain the positional nature of a good they must be exclusive in their distribution. The exclusiveness of a positional good can be strengthened if the good itself is retained as actionable item (a country home), and if the social mechanisms which allow people to compete for positional goods are private and competitive (fees for credentials).

When private and pay services are the norm money income becomes the social mechanism for access:

As cash income becomes increasingly dominant in governing consumption activities and attainment of social and economic position, so it must increasingly dominate

11 Ibid., p. 71. 
productive activities. If we grow more dependent on money for our life and leisure, we will also grow more dependent on money earnings. This is the internal logical in the process of privatization and more generally of commercialization. ${ }^{12}$

If the means to achieve a positional good are public and open for use then the usefulness of income declines. Also, if the positional goods become open for use, a country estate becomes public property, or if the circumstantial desirability, such as high income or luxurious benefits, of a position declines, the tendency towards commercialization is lessened.

The need to achieve a positional item as a personal consumption good drives and maintains private servicing. If the pay and benefits of an elite position are substantially different than the average individuals will seek additional private means to obtain such a position. This is most obviously demonstrated in the vast resources used to provide for the individual development and preparation of children for college admission. Even adults can partake of services to enhance their chance of obtaining these positions. Once again, a continual seeking of credentials appears to be the main mechanism.

The tendency towards privatization, which positional competition drives, obviously contributes to widening inequality and, secondarily, increased natural resource throughput to achieve money incomes. There is the additional result of the under-servicing of public provision, which Hirsch's many references to public transport speaks to. ${ }^{13}$ Increased capture of money income to compete for positional goods widens inequality, but if this competition results in the under-servicing of public provisions then inequality is exacerbated further as people receive fewer and lower quality goods and services.

Finally, the privatization of consumption crowds out friendship, since friendship is a non-

12 Ibid., p. 104.

13 Ibid., p. 90. 
private good:

The impact of time pressures on sociability - in the sense of friendliness, social contract, and mutual concern - is made particularly severe by the fact that these social relationship do not, by their nature, have the character of private economic goods: which is to say that the costs and benefits of specific actions do not fall primarily on those undertaking them. ${ }^{14}$

Overtime, the friendship "transaction" can be presumed, by its persistence, to be a net benefit on both sides. At any moment of time, though, the exchange is very unlikely to be reciprocally balanced. ${ }^{15}$

If people suffer time constraints due to increased competition then use of their leisure on an activity that does not conform to the cost-benefit calculations of private consumption goods. This means that friendship can appear to be a, so called, poor investment. A tendency towards private servicing can have the corrosive effect on political friendship and a decline in a solidaristic view of one's fellow societal members.

\section{3: Hirsch's Proposed Solutions to Social Scarcity}

This section will provide an overview of Hirsch's policy recommendations for dealing with social congestion. The next section will extend beyond Hirsch's recommendations and consider how the combined problems of social scarcity, inequality, and ecological decay can be handled collectively. 
Since the supply of positional goods cannot be increased, the attended means for obtaining them or their desirable features must be reduced if social congestion is to be minimized. Hirsch finds that if people can put their social interest before their individual interest it will reduce social congestion. ${ }^{16}$ This shift in objectives away from the private and toward the public cannot be achieved simply as an act of will, particularly since the reproduction of people's economic lives are structured by the piecemeal choices that reinforce flight from public services into private solutions that exacerbate social scarcity. Hirsch realizes that the institutions which influence people's choices must be crafted to facilitate such a change in personal objectives: 'Reducing the stakes for which the positional competition is played is probably the most promising available means of such guidance here'. ${ }^{17}$

Hirsch's recommendations are mainly ways to reduce the monetary desirability of positional posts and to reduce people's reliance on private services. Elite positions have desirable features intrinsic to their function, but many people may be attracted to these posts not for their features themselves, but because they are attracted to the high pay and the substantial in kind benefits. If people require increasing amounts of income to consume private services then they will seek high incomes through non-positional jobs too. This reliance on private provisioning will maintain the undesirable outcomes of public service flight. Even without positional competition, competition for private services results in the social waste of unmet expectations, since money earning ability as a rationing device will by necessity out price some competitors. Not all people who desire to live in Westchester or Winnetka can do so, but they will use up real resources in their attempts and will have to live with the social waste whether they succeed or not. Any approach to limiting social congestion has to lessen the appeal of positional posts and the need for private provisioning.

Hirsch recommended that pay in the positional sector be reduced and that payroll taxes should 
be used to minimize the flow of money income. Such measures should be applied nationally to avoid new positional posts arising due to their high pay. ${ }^{18}$ Hirsch found that such measures would attract people to the positions themselves instead of the secondary results (pay and benefits). Also, such measures would lead people to consider employment not simply as a means to achieve money incomes, but instead according to its function in the reproduction of society. This seemingly would facilitate people's choices in a more social and less self-interest direction. Reducing pay rates would lessen the credential race, due to the lower stakes of what is being screened for. It would increase the efficiency and personal benefits of higher education since there is less reason to pursue training in areas of little interest. $^{19}$

In addition to positional pay reduction, Hirsch recommended that increased public service provision will decrease the significance of money income. ${ }^{20}$ If people can receive adequate health care, education, housing, leisure, and transport through public services this reduces the need to compete for the private version. This would reduce real and social waste because the resources use to obtain the private good or service by individuals and the resources use in advertising and staffing the private item would be reduced. The complete replacement of these services and goods with public provision would be unnecessary, since any reduction in the need for money income will lessen the importance of positional posts and reduce the need to compete for private goods and services.

\section{4: Additional Solutions}

This paper has attempted to show that social scarcity, inequality, and ecological decay are not isolated problems. Rather it has been argued that anyone of these distributive problems exacerbate the other two. This section will first consider the effects Hirsch's solutions have on inequality and ecological

18 Ibid., pp. 183-184.

19 Ibid.

20 Ibid., p. 185. 
decay; next, it will consider possible solutions to minimize these problems that reach beyond Hirsch's recommendations.

Hirsch noted that his solutions will reduce inequality, since pay inequality is directly reduced and the impetus for high pay is minimized as positional posts become less attractive, at least from an income perspective, and there will be a reduced need for money income due to increased public provisioning. ${ }^{21}$ Ecological decay is driven by competition for position, to reduce inequality, and to maintain one's market share. Hirsch's recommendations would reduce, but do not eliminate, all three causes of ecological decay.

In addition to Hirsch recommendations, there are several possible policies that could be implemented to help reduce social scarcity, inequality, and ecological decay. This section will consider the policy recommendations of the job guarantee, cooperative businesses, reduction in company size, taxes, the creation of public corporations, and economic democracy. Industrial processes that reduce throughput or rely on renewable energy sources will not be discussed directly, even though these are very important to the problem of ecological decay. This paper's focus is on policy solutions not technical solutions.

The job guarantee is the provision of employment for all who desire it for an indefinite period of time, where the wage and material costs are paid by the federal or central government. ${ }^{22} \mathrm{~A}$ job guarantee could be administrated by a central, state, local government, or by a non-profit organization.

21 Ibid.

22 Arguments and analysis regarding the job guarantee can be found in these works: Mathew Forstater, 'Functional Finance and Full Employment: Lessons from Lerner for Today', Journal of Economic Issues, 33:2 (1999), pp. 475-482. Mathew Forstater, 'Public Employment and Environmental Sustainability', Journal of Post Keynesian Economics, 25:3 (2003) pp. 385-406. Philip Harvey, Securing the Right to Employment (Princeton, New Jersey: Princeton University Press, 1989). Fadhel Kaboub 'The Fiscal Cliff Mythology and the Full Employment Alternative: An Affordable and Productive Plan', Review of Radical Political Economics, 45:3 (2013), pp. 305-314. Hyman P. Minsky, Stabilizing an Unstable Economy (New York: McGraw Hill: 2008 [1986]). William Mitchell, 'The Buffer Stock Employment Model and the NAIRU: The Path to Full Employment', Journal of Economic Issues, 32:2 (1998), pp. 547-555. Warren Mosler, 'Full Employment and Price Stability', Journal of Post Keynesian Economics, 20:2 (1997-98), pp. 167-182. L. Randall Wray, Understanding Modern Money: The Key to Full Employment and Price Stability (Cheltenham, UK and Northampton, MA, USA: Edward Elgar, 1998). L. Randall Wray, Modern Money Theory: A Primer on Macroeconomics for Sovereign Monetary Systems (New York: Palgrave Macmillan: 2012). 
Most job guarantee plans propose that workers receive a wage that is not on par with private sector pay to prevent inflation and competition for workers. Most proposals recommend a flat basic wage which is not indexed to inflation and would be changed infrequently. Even with these pay limitations, the job guarantee would become the de facto minimum wage because all people who desired to work would be provided with a job. Nonetheless, the wages and benefits that job guarantee workers earn could be more substantial then the lowest paid jobs in the private sector. A job guarantee can thus institutionally change the nature of employment and the remuneration standards. Most plans for a job guarantee propose that the kinds of work offered should not be competitive with the private sector, but rather should supplement private provision with goods and services that will not be provided by the private sector (public goods) or goods and services which either price people out (health care for example) or provide substandard service when offered by the private sector (low cost child care being a prime example).

The kinds of goods and services that job guarantee works could provide are numerous: the construction and repair of public housing, public schools, and public hospitals, the provision of child and elder care, the building of new parks and public amenities, the provision of artistic and theatrical performances, fee public lectures, the supplementing of teaching, police, library, and firefighting work with assistants, forestry on public lands, the construction and maintenance of wilderness trails, minimize resource and energy use by recycling and repairing items, weatherizing homes, improving the energy efficiency of public buildings, driving and repairing public van pools, creating and maintaining public and rooftop gardens, monitoring and cleaning up environmental hazard sites, and land reclamation.

A job guarantee would have its most direct effect on the reduction of inequality by raising the money wages of those in the lowest income quintile. Job guarantee workers would also enjoy higher in-kind incomes with the goods and services they produce. People outside of the job guarantee would 
also enjoy these benefits. The work done by job guarantee workers could assist in transitioning a society toward a sustainable economy through the repair and maintenance of natural resources and sustainable practices. In addition to increased public services provision, which Hirsch recommended, the goods and services, which job guarantee workers provide, would further lessen the need for money income and reduce the competition for positional posts. A job guarantee could reduce the distributive conflicts of social scarcity, inequality, and ecological decay.

Cooperative ventures, where workers own their own company, could help reduce inequality by reducing the tendency towards positional competition. Even if the pay rates of positional posts are reduced and public provision is increased there could be substantial numbers of people who desire the actual practice of these posts, where problem solving, decision making, creativity, and management are more common. Cooperatives could provide people the opportunity to engage in these activities to a greater extent than in regular wage positions. Workers who own and operate their own companies would make decisions concerning product development, market placement, work conditions, and would reap the profits for their efforts. These aspects would make cooperatives attractive working environments for people who seek greater challenges and environments which are similar to current positional posts. It is unclear if cooperatives themselves would reduce ecological decay; but if they reduced inequality and social scarcity they would secondarily reduce the drive for money income and the accompanying natural resources throughput.

Hirsch recommended that positions with smaller stakes in play will reduce positional competition. In light of this idea, reducing company size by breaking up existing units could not only increase the number of posts available but would also reduce the monetary stakes involved. Financial institutions have a tendency towards consolidation, which does not necessarily result in better services for the customers. Reducing bank size would create more opportunities for individuals to participate as owners and executives. The same could be said for the majority of services: retail, wholesale, 
television, and newspapers. If possible, manufacturing and processing being reduced to regional, if not local operations, would be desirable for the same reasons. The effects of such reductions in company scale would have on inequality and ecological decay are unclear, but, a leveling on income, on a national scale, may be a welcome result. The most pronounced affects would be a reduction in competition for posts, which would become more numerous with better spatial distribution.

Subsidies, taxes, and fines, in addition to the payroll taxes Hirsch desired, could be used to shape behavior and not to fund revenue. ${ }^{23}$ These measures should be used to prevent the development of positional competition, inequality, and ecological decay. They should not be used as a means to circumvent their limitation. For example, a tax could be levied if a company has a pay range outside of a desired band, but, a subsidy for conversion to a more energy efficient fuel system should not be used to increase the pay for elite positions and widen a company's pay scale. Nonetheless, it is desirable for the alleviation of the three distributive conflicts considered here, that both pay scales should be capped and limited in range, and that measures which reduce ecological decay be implemented. With this in mind, a policy that provides certain incentives should be minimized in its implementation or with additional policy measures. The taxes and subsidies mentioned here are not intended to promote undesirable and counterproductive actions, but that, of course, could be unintended results.

In addition to taxes to limit the pay range of a company, companies could be taxed for using excessive resources, and having work weeks that are too long (since energy must be used to light, heat, and cool the buildings and workers must use energy to travel to work). Taxes on throughput would penalize the use of natural resources. ${ }^{24}$ With taxes on pay above a certain amount and on throughput, earnings could be invested in sustainable practices, saved, or dispersed as dividends. Such actions

23 For readers who are interested in this idea see the following readings on functional finance and taxation: Abba P. Lerner, 'Functional Finance and the Federal Debt', Social Research, 10:1 (1943), pp. 38-51. Beardsley Ruml, 'Taxes for Revenue are Obsolete', American Affairs, 8:1 (1946), pp. 35-39.

24 Herman Daly, Beyond Growth (Boston: Beacon Press,1996), p. 90 
could promote investment and would be a benefit to stockholders with low earnings. If speculation is a concern then trading taxes could be levied as well. Limiting speculation and restricting investment to more conservative structures could be promoted through increased use of discount window reserve lending. ${ }^{25}$

Estate taxes could be levied to minimize the positional advantaged granted to the children of the wealthy. Inherited wealth gives the recipient an advantage, but it drives competition for positional goods and credential wars because those who are not wealthy must compete with generations of accumulated wealth. A more level playing field would reduce the stakes. Taxes on lower incomes could be reduced if they occur within a set band and the progressivity of taxation could increase faster than income at a certain threshold. Consumption taxes could be used to limit conspicuous consumption and reduce throughput. This could help motivate people to save income and consume public goods and public services to reduce people's reliance on income. Auto taxes, on fuel, road use, parking, and ownership, could reduce private motorized transport and promote public transport use, walking, and cycling. These measures could tax inequality beyond a particular range, the accumulation of personal wealth, private consumption, and natural resources throughput, but would not tax saving, production without throughput use, and the use of public services.

The use of subsidies to influence behavior could run into the problem that the subsidy would be taxed away by the above measures. It may be more useful for public agencies and job guarantee workers to produce the desired results. For example, subsidies to build roof gardens or to plant trees may not result in the gardens or trees if the subsidies are taxed away. It would be more reliable to have a public agency identify acceptable roofs for gardens or areas for tree planting and then implement the outcome. Similar projects could be used for the construction of housing, care facilities, schools, parks, and other leisure amenities. Private companies may be unwilling to commit resources to projects due to 25 Minsky, Stabilizing an Unstable Economy, op. cit., p. 358. 
the taxation effects. In addition, society wide goals cannot be left to private initiative if the secondary effects of money income accumulation are to be avoided. Smaller business will have smaller effects, thus publicly orchestrated goals will need to fill the gap in areas of need. There is no reason to leave attaining the public good to private initiative if the results are inadequate or counterproductive.

Many of the above measures stifle demand, as is their intended effect, in order to reduce inequality, ecological decay, and positional competition. All three problems are driven by money income accumulation and intensification of private servicing. Any slack in demand cannot be driven by typical stimulus spending, which promotes consumption, natural resources throughput, and usually increases the incomes of the currently employed. ${ }^{26}$ Demand measures can be more targeted towards the unemployed and less ecological destructive processes can be promoted through the use of a job guarantee. Employing people in the production of services to be dispensed for free and paying these workers wages that will not be competitive with positional salaries will help close the job gap, while minimizing reliance on the cash nexus. Full employment does not have to be attained at the expense of greater equality or ecological sustainability.

Certain industries with large capital costs and natural monopolies could be replaced with publicly controlled firms. Industries with monopoly pricing power would be constrained by the above taxation measures, at least regarding pay rates. The main reason for the establishment of publicly controlled firms is not necessarily to structure their output to minimize ecological damage, which could be promoted though taxation, rather these industries should produce to meet public needs. Production for public need would minimize the need for money income to obtain these services. The most obvious candidates for conversion into publicly controlled firms are intercity rail transport and the public utilities of communication, water, and power. Fines could be levied for high use rates instead of fees at

26 Pavlina Tcherneva, 'Reorienting Fiscal Policy: A Critical Assessment of Fiscal Fine-Tuning', The Jerome Levy Economics Institute of Bard College, Working Paper, no. 772, (2013). 
the point of service. The notion being that public utilities are for public benefit and overuse degrades their usefulness. This practice would stress the public ownership and social nature of the use of public utilities. Travel between cities, communication, and energy are institutions that structure our social interactions and should be recognized as public assets. Water supplies are part of our biological interchange with nature and other humans, where one person's use affects other people's use.

Finally, increasing people's chances of deciding on the structure and pace of economic development could reduce positional competition. Economic democracy, either electoral or direct, would allow people to participate in how their society develops. This would be a drastic change from the current state of affairs, where decisions are made by private planning and sales effort committees. The affect economic democracy will have on inequality and on ecological decay is impossible to predict. The result of greater democracy in choosing the path of a nation's economic development could result in decisions that exacerbate these problems, since people may choose high incentive pay and high throughput outcomes.

\section{Conclusion}

When Social Limits to Growth was published in 1976 Hirsch noted that the social congestion could be a bigger problem for society than ecological decay. ${ }^{27}$ Many would disagree with his analysis today. It is not that Hirsch was incorrect in his evaluation of the severity of these two problems. Rather, he missed the consideration that positional competition and ecological decay are linked distributive problems both of which have economic growth at their cause. As Hirsch identified, economic growth is not a phenomenon that occurs outside of society's institutions. Rather, what kind of economic growth occurs and how the benefits and detriments are distributed are results determined by the existing social institutions. Why do people seek growth of income when the results may be detrimental to their well-

27 Hirsch, Social Limits to Growth, op. cit., p. 4. 
being? Institutionally the set of choices are compete or drop out, with dropping out being a derided option. The difficulty of choosing dropping out is even greater for people with children. Can a guardian willfully not seek increasing money income to allow their children to enter the credential race, especially when inequality has a tendency to increase under the current institutional arrangements?

A solution to any of the three distributive problems must take the other two into account to avoid exacerbating them. If one wishes to increase real living standards by promoting economic growth, social congestion and ecological decay can be exacerbated. If one wishes to reduce ecological decay by limiting economic growth, inequality can intensify with increasing unemployment and social scarcity can intensify by increasing the stakes for elite positions and paid employment. If one wishes to mediate social scarcity through taxation on particular positions, this may reduce demand and intensify inequality and shift attempts to gain income towards ecologically destructive processes.

Designing institutions to structure economic growth that decrease natural resources throughput while lessening the need for credentials and money income it is necessary to tackle all three problems. Correctly crafted taxes can assist in achieving these goals, but the most important measure is reducing the stakes played for. If people can have employment and service guarantees there is less of a need to find increasing sources of income to compete for position and services. A job guarantee and increased public provision are central to any program to lessen distributive conflicts since they provide economic security and socially acceptable living standards; both of which reduce the necessity for position and the higher than average money income that currently is attached to it. 
